\title{
Geriatric Profile of Elderly Patients Treated For Pancreatic Cancer: The Oncogepan Database
}

\author{
Alban Macagno ${ }^{1}$, Elodie Cretel Durand ${ }^{2}$, Emilie Nouguerede ${ }^{3}$, Cecile Braticevic ${ }^{1}$, Maud \\ Cecile $^{1}$, Mohamed Gasmi ${ }^{4}$, Jean-François Seitz ${ }^{4}$, Emmanuelle Norguet ${ }^{4}$, Camille Sibertin- \\ Blanc $^{4}$, Vincent Moutardier ${ }^{5}$, Marc Giovannini ${ }^{6}$, Jean-Luc Raoul ${ }^{1}$, Jean-Robert Delpero ${ }^{7}$, Lilian \\ Laborde $^{8}$ and Frédérique Rousseau ${ }^{1}$ \\ ${ }^{1}$ Department of Oncology, Paoli-Calmettes Institute, Marseille France \\ ${ }^{2}$ Transveral Oncogeriatric Unit, Assistance Publique Hôpitaux de Marseille, Marseille France \\ ${ }^{3}$ Inserm, UMR 911-CRO2, Marseille France \\ ${ }^{4}$ Department of Digestive Oncology, Assistance Publique Hôpitaux de Marseille, Marseille, France \\ ${ }^{5}$ Department of General and Digestive Surgery, Assistance Publique Hôpitaux de Marseille, Marseille, France \\ ${ }^{6}$ Department of Endoscopy, Paoli-calmettes Institute, Marseille, France \\ ${ }^{7}$ Department of Surgical Oncology, Paoli Calmettes Institute, Marseille, France \\ ${ }^{8}$ Data Management Unit, Department of Clinical Research and Innovation, Paoli-Calmette Institute, Marseille, France
}

Received: April 20, 2017; Accepted: June 21, 2017; Published: September 19, 2017

*Corresponding author: Alban Macagno, Department of Oncology, Paoli-Calmettes Institute, Marseille France, Tel: +33491223847; Fax: +33491223856; E-mail: alban.macagno@gmail.com

\begin{abstract}
Objectives: The aim of the ONCOGEPAN database is to describe the geriatric parameters of the elderly population diagnosed with pancreatic cancer, and to evaluate the geriatric parameters that may impact on survival.
\end{abstract}

Methods: Between 2012 and 2014, 51 patients over 70 years of age, with pancreatic cancer, who were treated at 2 centers (the Assistance Publique des Hôpitaux de Marseille and the Paoli-Calmettes Institute), and who received a Comprehensive Geriatric Assessment (CGA) were analyzed.

Results: The median overall survival was determined to be 4.9 months. By univariate analysis, the geriatric parameters affecting overall survival were: dependence of daily living activities (ADL) ( $p<.0001$; IC95\% 1.98-8.07); the presence of cognitive impairments $(\mathrm{p}=0.029$; IC95\% 1.08-4.23); functional status with a "Timed up and go test $>20$ sec $^{\prime \prime}(\mathrm{p}<.0001$; IC95\% 2.42-12.74), and an inability to maintain a unipodal stance ( $\mathrm{p}=0.001$; IC95\% 1.64-6.78). By multivariate analysis, only the metastatic status (HR 5.97; IC95\% 1.87-19.07; $p=0.003$ ) and a Balducci score of 3 (HR 3.53; IC95\% 1.45$8.60 ; p=0.005$ ) were identified as predictive factors for survival.

Conclusion: Autonomy, cognitive impairments, and functional frailty are geriatric parameters who affect survival. The existence of these geriatric fragilities identified by the CGA must challenge an aggressive cancer treatment, in pathology where the median survival is low.

Keywords: Pancreatic Neoplasm; Aged; Geriatric Assessment; Therapeutics; SurvivalRoasting; Browning index; Colour

\section{Introduction}

Pancreatic cancer is the fourth leading causing of death in the Western world. The prognosis is poor, with a 5 year survival rate under 5\% [1]. In 2012, the incidence of pancreatic cancers in Europe was in the order of 103,773 cases [2]. The median age at diagnosis is 72 years [3] and it was estimated in the recent SEER analysis [4] that more than $31 \%$ of adult patients diagnosed in the US with a pancreatic cancer were more than 74 years old. Surgery is considered to be the only curative option, although a mere $20 \%$ of patients are eligible for surgical exeresis. Most often, the disease is discovered at a locally advanced or metastatic stage, and palliative care is the only option, with median survival times of about 9 to 10 months. The standard therapy in this situation is chemotherapy [5].

In elderly subjects, for whom quality of life is the foremost concern, single agent chemotherapy with GEMCITABINE, for which tolerance and efficacy have been assessed, constitutes the best therapeutic option [6-8]. Data regarding elderly subjects afflicted with pancreatic cancers are limited. Indeed, these individuals are often excluded or "under-represented" in clinical trials. A major advance in the treatment of metastatic pancreatic cancer occurred as a result of the demonstration of the superiority of the FOLFIRINOX regimen as compared to GEMCITABINE9. In the study of Conroy and al., only patients who were in very good physical health and less than 76 years of age could be included. 
Yet a sub-group analysis showed that in the group of patients $>65$ years of age there was an increase in survival with FOLFIRINOX versus GEMCITABINE. For this age group, it has been clearly shown that patients are typically treated less aggressively, with non-optimal surgical procedures and chemotherapy regimens 10 .

Subjects who are more than 70 years of age constitute a population that is very heterogeneous and difficult to treat. Treatment of elderly patients afflicted with pancreatic cancer, who at the clinical level most often undergo rapid progression of their pathology, is a challenge for oncologists. What is required is to provide them with a personalized treatment with a dual purpose: disease control and retention of autonomy.

Following a retrospective study of elderly patients afflicted with pancreatic cancer who were treated between 2002 and 2012 at the Paoli-Calmettes Institute (PCI) 11 and in keeping with the recommendations of the French National Cancer Institute ("INCa"), we decided to provide a standardized geriatric assessment to these patients.

Marseilles' comprehensive cancer center (Site de Recherche Intégréen Cancérologie- (SIRIC) and the PACA west Oncogeriatric Coordination Unit (Unité de Coordination OncoGériatrique(UCOG) compiled these assessments in the ONCOGEPAN database that was established in 2013. The aims of this data base are to describe the geriatric parameters of the elderly population diagnosed with pancreatic cancer, and to evaluate the geriatric parameters that may impact on survival.

\section{Materials and Methods}

Population: Our study focused on elderly patients over 70 years of age, for documented or suspected pancreatic cancer, who were referred to an oncogeriatrician for a full Comprehensive Geriatric Assessment (CGA) in two oncology specialized centers in Marseille (the Assistance Publique des Hôpitaux de Marseille (APHM) and the Paoli-Calmettes Institute(PCI)) between January 2012 and September 2014.

Data collection: All patients were notified that their clinical information was being collected through an e-CRF (SSI mode, encrypted transmission) with the CLINSIGHT software into an ORACLE database hosted by a secure server (CNIL authorization $\mathrm{n}^{\circ} \mathrm{DR}-2014-422$ ).

Collected data: CGA components such as socio-demographic data, dependence in activities of daily living (ADL) [12] and instrumental activities (IADL) [13], functional (gait speed, the "Timed up and go test", and one-leg balance test)[14-17], cognitive, mood and nutritional status (MMSE, Geriatric Depression Scale (GDS))[18,19], Mini-Nutritional Assessment (MNA), predictive scores (the ONCODAGE scale [20,21], Balducci score [22] and Charlson index [23]) and clinical data were collected prospectively.

Statistical analysis: SPSS 17.0 for Windows and Stata were used for analysis. Proportions and their confidence intervals were calculated for all categorical variables. The median followup, and the average age was also calculated. Kaplan-Meier and Cox models were used to determine the probability of survival as a function of time since inclusion in the cohort (CGA date) to the last event (death, lost contact, or time point: 30th September 2014) and was compared to overall survival as a function of the time since diagnosis to the last event. The log-rank test was used to compare survival curves according to various factors. These statistical analyses were conducted at a significance level of 0.05 .

\section{Results}

Between 2012 and 2014, 51 patients ( 22 women and 29 men) who were treated at 2 centers (APHM and the PCI), who were 70 years of age or older, who were afflicted with histologically proven pancreatic cancer, and who received Acga were analyzed.

The demographic and the oncological characteristics of our population are presented in table 1 . Their median age was 79.7 (ranging from 71 to 90 years of age). The majority of the patients had locally advanced or metastatic disease (40 patients) and in light of this they received palliative care. Seven patients underwent surgical intervention, 26 received a chemotherapy treatment, and for 18 the treatment amounted to support care only.

The geriatric characteristics are summarized in table 1. Most of the elderly subjects (64.4\%) were autonomous in regard to activities of daily living (ADL $\geq 5.5 / 6$ ), but were dependent (68.9\% of the patients) for their instrumental activities of daily living (IADL). $70.2 \%$ of the subjects did not exhibit cognitive impairments (MMSE >24) although 40\% of them suffered from depressive moods (GDS15 $\geq 5$ ). In regard to testing of physical performance, $64.9 \%$ succeeded with the "Timed up and go test ", $51.1 \%$ could maintain a unipodal stance (> 5 sec.), while $68.4 \%$ had an abnormal gait speed $(<1 \mathrm{~m} / \mathrm{s})$.The vast majority of the patients (72.5\%) suffered from malnutrition (Alb. $<35 \mathrm{~g} / \mathrm{L}$ and/or MNA $<17$ and/or IMC $<21$ ), of whom $43.1 \%$ had severe malnutrition (Alb. $<30 \mathrm{~g} / \mathrm{Land} /$ or IMC $<18$ ). The majority of the patients (54.9\%) were considered to be frail at the geriatric level, with a Balducci score of 3.

In regard to specific treatments for the patients, oncologists were able to prescribe an oncological treatment for $87 \%$ of the patients. The opinion of the geriatrician was in accordance with the oncologist in $79 \%$ of cases. $50 \%$ of the concordant opinions carried a recommendation by the geriatrician (Figure 1) (complementary examinations, malnutrition management, treatment adaptation and rehabilitation) that brought about an alteration of the oncologists' proposals for $34 \%$ of the patients: 4 surgical interventions and 11 chemotherapies were recused following complementary examinations. The geriatrician issued an unfavorable opinion in regard to the recommended oncological treatment for $21 \%$ of the patients (1 surgical intervention, 1 adjuvant chemotherapy, and 7 chemotherapy treatments). 
Table 1: Demographic, oncological, and geriatric characteristics

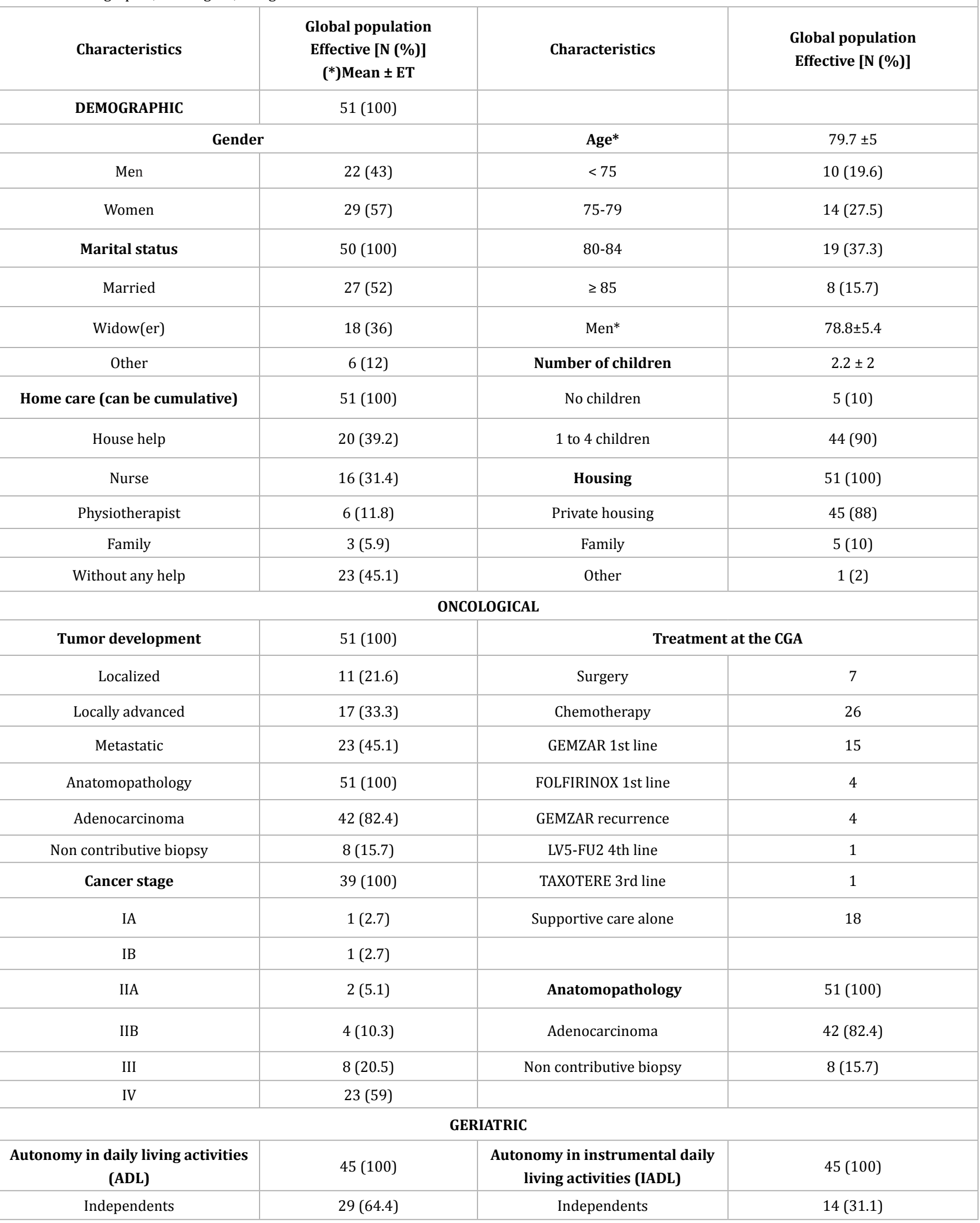




\begin{tabular}{|c|c|c|c|}
\hline Dependents & $16(35.6)$ & Dependents & $31(68.9)$ \\
\hline $\begin{array}{c}\text { Cognitive troubles (MMSE } \leq 24 ; \\
\text { mini } \operatorname{Cog} \leq 4)\end{array}$ & $47(100)$ & Mood & $34(100)$ \\
\hline Normal cognitive status & $33(70.2)$ & Non depressive & $19(55.9)$ \\
\hline Suspicion of cognitive troubles & $14(29.8)$ & Depression & $15(44.1)$ \\
\hline \multicolumn{2}{|c|}{ Nutritional status } & \multicolumn{2}{|c|}{ Functional Status } \\
\hline Weight loss percentage* & $10.5 \pm 8.1$ & Timed up and go Test & $37(100)$ \\
\hline IMC* & $25.8 \pm 7.1$ & Normal & $24(64,9)$ \\
\hline Albumin* & $31,7 \pm 7,9$ & Abnormal (>20s) & $13(35,1)$ \\
\hline Normal nutritional status & $14(27,5)$ & One-leg balance test & $45(100)$ \\
\hline Malnutrition & $15(29,4)$ & Maintained & $23(51.1)$ \\
\hline Severe Malnutrition & $22(43,1)$ & Not maintained & $22(49.9)$ \\
\hline G8 (Oncodage) & $45(100)$ & Gait speed & $19(100)$ \\
\hline$\leq 14$ & $43(95.6)$ & Normal & $6(31.6)$ \\
\hline$>14$ & $2(4.4)$ & Abnormal $(<1 \mathrm{~m} / \mathrm{s})$ & $13(68.4)$ \\
\hline Performance status & $51(98.1)$ & G8 (Oncodage) & $45(100)$ \\
\hline OMS 0 & $3(5.9)$ & $\leq 14$ & $43(95.6)$ \\
\hline OMS 1 & $19(37.3)$ & $>14$ & $2(4.4)$ \\
\hline OMS 2 & $11(21.6)$ & Balducci score & $52(100)$ \\
\hline OMS 3 & $17(33.3)$ & Balducci Score 1 & $4(7.8)$ \\
\hline \multirow[t]{2}{*}{ OMS 4} & $0(0)$ & Balducci Score 2 & 19 (37.3) \\
\hline & & Balducci Score 3 & $28(54.9)$ \\
\hline
\end{tabular}

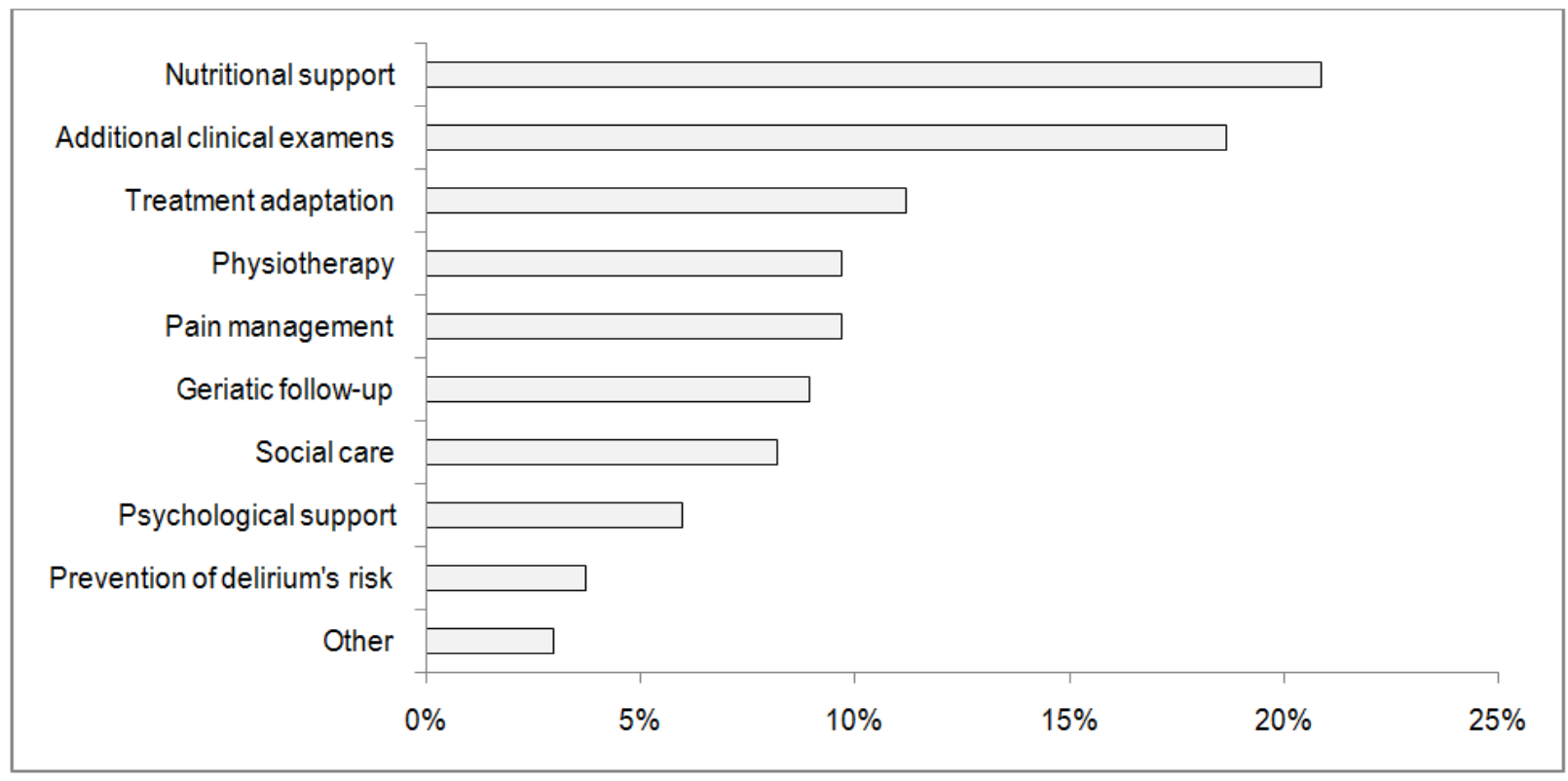

Figure 1: The most frequent recommendations of supportive care given by the oncogeriatrician to our population 
The median overall survival was determined to be 4.9 months. The median survival was 11.4 months and 8.3 months for patients treated by surgery and chemotherapy, respectively.

By univariate analysis, the geriatric parameters affecting overall survival were: dependence of daily life activities ( $\mathrm{p}<.0001$; IC95\% 1.98-8.07); the presence of cognitive impairments ( $\mathrm{p}=0.029$; IC95\% 1.08-4.23);functional status with a "Timed up and go test >20sec" (p<.0001; IC95\% 2.42-12.74), and an inability to maintain a unipodal stance ( $\mathrm{p}=0.001$; IC95\% 1.646.78) (Table 2 and figure 2).

By multivariate analysis, only the metastatic status (HR 5.97; IC95\% 1.87-19.07; $\mathrm{p}=0.003$ ) and a Balducci score of 3 (HR 3.53; IC95\% 1.45-8.60; $\mathrm{p}=0.005$ ) were identified as predictive factors for survival. A G8<14 cannot be considered to be a marker that impacts on overall survival (HR 0.87; IC95\% 0.20-3.67; p=0.851) (Figure 3).

Table 2: Multivariate analysis of the prognostic factor (Cox model)

\begin{tabular}{|c|c|c|c|c|c|c|c|c|c|}
\hline $\begin{array}{l}\text { Characteristics } \\
\text { Global survival }\end{array}$ & HR & IC95\% & p-value & $\mathbf{N}$ & $\begin{array}{l}\text { Univariate } \\
\text { analysis }\end{array}$ & HR & IC95\% & p-value & $\mathbf{N}$ \\
\hline \multicolumn{5}{|c|}{ Autonomy in daily living activities (ADL) } & \multicolumn{5}{|c|}{ Autonomy in instrumental daily living activities (IADL) } \\
\hline Independents & \multicolumn{3}{|c|}{ Reference } & 29 & Independents & \multicolumn{3}{|c|}{ Reference } & 14 \\
\hline Dependents & 4.004 & $1.986-8.072$ & $<0.0001$ & 16 & Dependents & 1.41 & $0.706-2.814$ & 0.330 & 31 \\
\hline \multicolumn{5}{|c|}{ Cognitive troubles $(M M S E \leq 24 ; \operatorname{miniCog} \leq 4)$} & \multicolumn{5}{|c|}{ Mood } \\
\hline $\begin{array}{c}\text { Normal cognitive } \\
\text { status }\end{array}$ & \multicolumn{3}{|c|}{ Reference } & 33 & Non depressive & \multicolumn{3}{|c|}{ Reference } & 19 \\
\hline $\begin{array}{c}\text { Suspicion of cognitive } \\
\text { troubles }\end{array}$ & 2.14 & $1.083-4.231$ & 0.029 & 14 & Depression & 1.927 & $0.887-4.187$ & 0.098 & 15 \\
\hline \multicolumn{5}{|c|}{ Functional Status } & \multicolumn{5}{|c|}{ Nutritional status } \\
\hline \multicolumn{5}{|l|}{ Timed up and go Test } & $\begin{array}{l}\text { Normal nutritional } \\
\text { status }\end{array}$ & \multicolumn{3}{|c|}{ Reference } & 14 \\
\hline Normal & \multicolumn{3}{|c|}{ Reference } & 24 & Malnutrition & 1.356 & $0.554-3.321$ & 0.505 & 15 \\
\hline Abnormal (>20s) & 5.555 & $2.421-12.74$ & $<0.0001$ & 13 & Severe malnutrition & 1.995 & $0.892-4.463$ & 0.093 & 22 \\
\hline \multicolumn{5}{|c|}{ One-leg balance test } & \multicolumn{5}{|c|}{ Multivariate analysis } \\
\hline Maintained & \multicolumn{3}{|c|}{ Reference } & 22 & & & \multirow{2}{*}{ IC95\% } & \multirow{2}{*}{ p-value } & \multirow{2}{*}{$\mathbf{N}$} \\
\hline Not maintained & 3.339 & $1.644-6.782$ & 0.001 & 23 & & HR & & & \\
\hline \multicolumn{5}{|c|}{ Gender } & \multicolumn{5}{|c|}{ Gender } \\
\hline Men & \multicolumn{3}{|c|}{ Reference } & 22 & Men & \multicolumn{3}{|c|}{ Reference } & 22 \\
\hline Women & 1.306 & $0.687-2.480$ & 0.415 & 29 & Women & 1.651 & $0.786-3.464$ & 0.185 & 29 \\
\hline \multicolumn{5}{|c|}{ Age } & \multicolumn{5}{|c|}{ Age } \\
\hline $70-74$ & \multicolumn{3}{|c|}{ Reference } & 10 & $70-74$ & \multicolumn{3}{|c|}{ Reference } & 10 \\
\hline $75-79$ & 1.427 & $0.588-3.462$ & 0.431 & 14 & $75-79$ & 2.419 & $0.785-7.457$ & 0.124 & 14 \\
\hline $80-84$ & 0.806 & $0.330-1.967$ & 0.636 & 19 & $80-84$ & 1.266 & $0.441-3.633$ & 0.661 & 19 \\
\hline 85 and over & 0.597 & $0.194-1.834$ & 0.368 & 8 & 85 and over & 1.087 & $0.308-3.833$ & 0.897 & 8 \\
\hline \multicolumn{5}{|c|}{ Balducci score } & \multicolumn{5}{|c|}{ Balducci score } \\
\hline $1-2$ & \multicolumn{3}{|c|}{ Reference } & 23 & $1-2$ & \multicolumn{3}{|c|}{ Reference } & 23 \\
\hline 3 & 1.508 & $0.800-2.845$ & 0.204 & 28 & 3 & 3.535 & $1.453-8.600$ & 0.005 & 28 \\
\hline & Tumol & velopment & & & & Tumor & levelopment & & \\
\hline
\end{tabular}




\begin{tabular}{|c|c|c|c|c|c|c|c|c|c|}
\hline Localized & \multicolumn{3}{|c|}{ Reference } & 11 & Localized & \multicolumn{3}{|c|}{ Reference } & 11 \\
\hline Locally advanced & 2.047 & $0.727-5.763$ & 0.175 & 17 & Locally advanced & 3.365 & $0.997-11.365$ & 0.051 & 17 \\
\hline Metastatic & 2.978 & $1.117-7.942$ & 0.029 & 23 & Metastatic & 5.974 & $1.870-19.078$ & 0.003 & 23 \\
\hline \multicolumn{5}{|c|}{ G8 $\leq 14$} & \multicolumn{5}{|c|}{ G8 $\leq 14$} \\
\hline Normal & \multicolumn{3}{|c|}{ Reference } & 2 & Normal & \multicolumn{3}{|c|}{ Reference } & 43 \\
\hline Abnormal & 0.872 & $0.207-3.673$ & 0.851 & 43 & Abnormal & 1.267 & $0.243-6.599$ & 0.778 & 2 \\
\hline
\end{tabular}
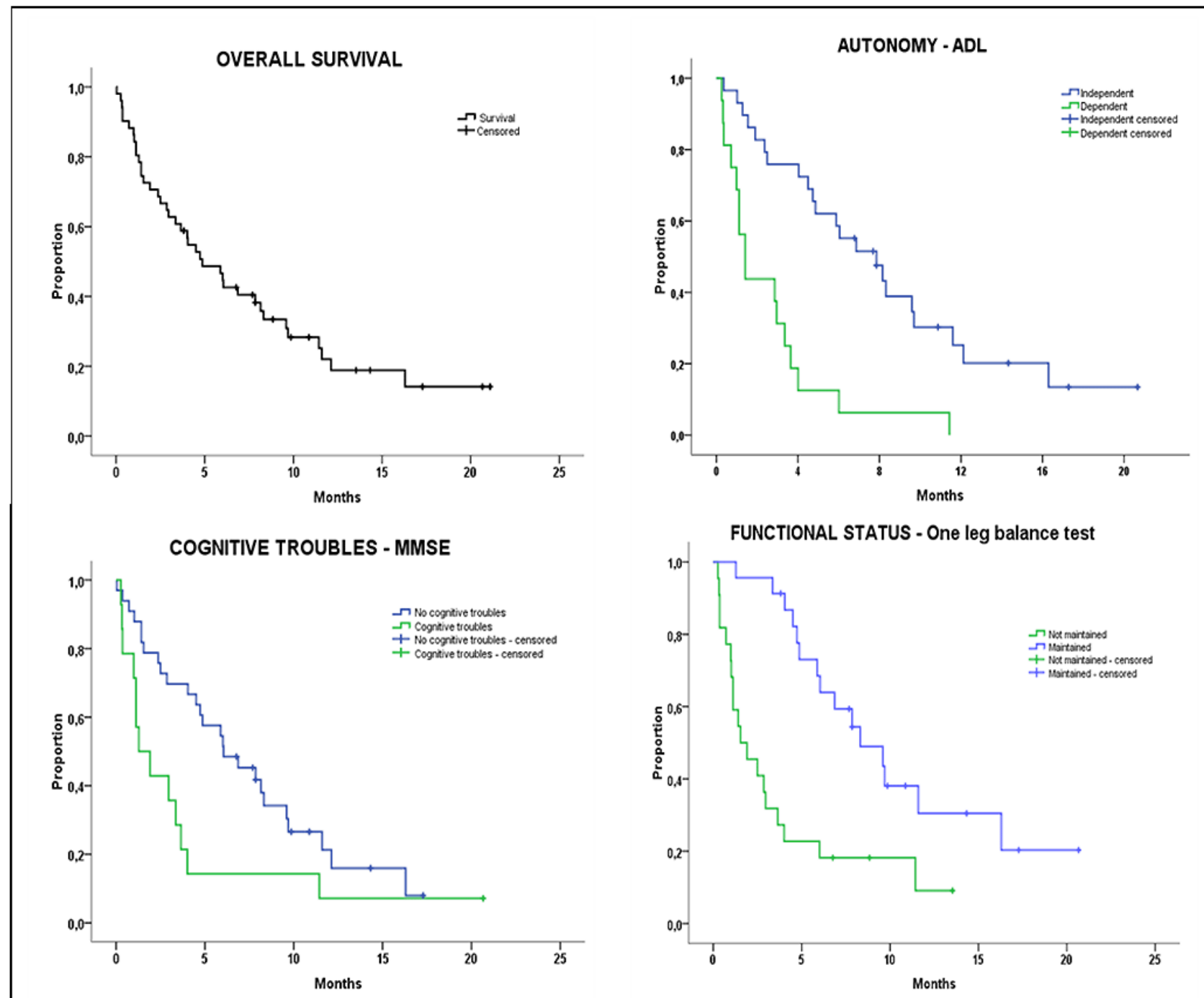

Figure 2: Survival analysis according to the geriatric criteria. Kaplan-Meier analysis of our population in terms of overall survival and according to the patients' geriatric status (Log Rank analysis: Autonomy ( $A D L \leq 5), p<0.0001$; Cognitive impairments (MMSE $\leq 24$ ), $p=0.025$; One leg-balance test (maintained 5s), $\mathrm{p}<0.0001$ )

Citation: Macagno A, Cretel Durand E, Nouguerede E, Braticevic C, et al. (2017) Geriatric Profile of Elderly Patients Treated For Pancreatic Cancer: The Oncogepan Database. Gastroenterol Pancreatol Liver Disord 4(6): 1-10. DOI: http://dx.doi.org/10.15226/2374- 


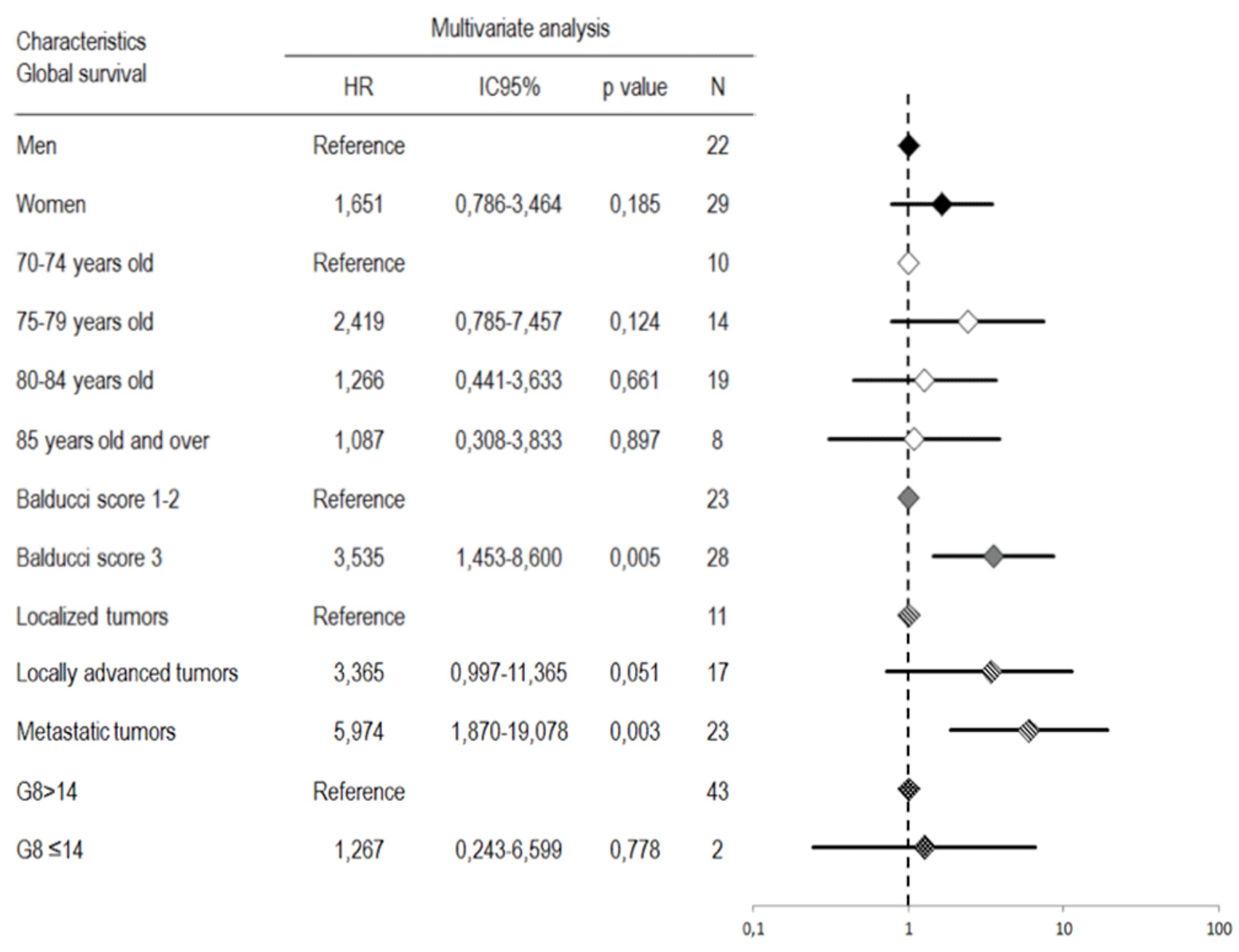

Figure 3: Multivariate analysis

\section{Discussion}

In this population of patients of 70years of age and afflicted with various stages of pancreatic cancer, the geriatric parameters that impact on survival by univariate analysis regardless of the therapies used are: dependence of the elderly subject, presence of cognitive impairments, and lack of ability in regard to the physical performance tests ("Timed up and go test" and "one leg balance test").A multivariate analysis of these parameters was not achievable since these various criteria are not independent. In this sense, one cannot directly identify these geriatric parameters as predictive factors of survival.

We chose to analyze survival from the date of the CGA, which was a time when the geriatric frailty was identified. Compared to the overall population of patients treated for pancreatic cancer, our population of elderly subjects exhibited a poor overall survival rate (4.9 months vs. 10 months). However, overall survival since diagnosis was closest to data in the current literature (Table 3).
Compared to literature, the overall survival data in our study could seem low: 4.9 months median survival in overall population, 11.4 months in surgical patients, 8.3 months in patients treated systemically and only 1.1 months for patients who received exclusive palliative care. The bias observed comes from the period starting point chosen for our analysis. We aimed to analyze geriatric frailties highlighted by the CGA, as such, univariate and multivariate analysis wouldn't be relevant looking at a period of time since diagnosis given, on average, 3.6 months before CGA (min: 1 day; Max: 8 years). In addition to this problematic, the poor overall survival of our group as a whole is largely due to the 18 patients who were directly assigned palliative care, the tumor stages (60\% stage IV) and frailty at the time of the CGA (54.9\% Balducci score 3; 72.5\% malnourished patients) need to be taken into account. Despite the poor prognosis profile of our population, when considering survival analysis since diagnosis, patients treated in the 2 centers showed survival comparable to the literature (Table 3). 
Table 3: Comparison of the population's overall survival since CGA or diagnosis

\begin{tabular}{|c|c|c|c|c|c|c|c|c|}
\hline & \multicolumn{2}{|c|}{$\begin{array}{c}\text { Global population } \\
\text { Effective }[N(\%)] \\
(*) \text { Mean } \pm \text { ET }\end{array}$} & \multicolumn{2}{|c|}{$\begin{array}{c}\text { Surgical patients } \\
\text { Effective }[N(\%)] \\
\left(^{*}\right) \text { Mean } \pm \text { ET }\end{array}$} & \multicolumn{2}{|c|}{$\begin{array}{c}\text { Systemically treated } \\
\text { patients } \\
\text { Effective [N (\%)] } \\
\left({ }^{*}\right) \text { Mean } \pm \text { ET }\end{array}$} & \multicolumn{2}{|c|}{$\begin{array}{c}\text { Palliative care only } \\
\text { Effective }[\mathrm{N}(\%)] \\
(*) \text { Mean } \pm \text { ET }\end{array}$} \\
\hline & $\begin{array}{c}\text { Overall } \\
\text { survival } \\
\text { since CGA }\end{array}$ & $\begin{array}{c}\text { Overall } \\
\text { survival } \\
\text { since } \\
\text { diagnosis }\end{array}$ & $\begin{array}{c}\text { Overall } \\
\text { survival } \\
\text { since CGA }\end{array}$ & $\begin{array}{c}\text { Overall } \\
\text { survival } \\
\text { since } \\
\text { diagnosis }\end{array}$ & $\begin{array}{c}\text { Overall } \\
\text { survival since } \\
\text { CGA }\end{array}$ & $\begin{array}{c}\text { Overall } \\
\text { survival } \\
\text { since } \\
\text { diagnosis }\end{array}$ & $\begin{array}{c}\text { Overall } \\
\text { survival } \\
\text { since CGA }\end{array}$ & $\begin{array}{c}\text { Overall } \\
\text { survival since } \\
\text { diagnosis }\end{array}$ \\
\hline Min. (months) & $<1$ & $<1$ & $<1$ & $<1$ & 1.3 & 1.5 & $<1$ & $<1$ \\
\hline Max. (months) & 21 & 39 & 17 & 51 & 21 & 45.5 & 12 & 24 \\
\hline $\begin{array}{l}\text { Median } \\
\text { (months) }\end{array}$ & 4.9 & 16 & 11.4 & 31.6 & 8.3 & 19.8 & 1.1 & 3.3 \\
\hline $\begin{array}{l}\text { Standard } \\
\text { deviation } \\
\text { (months) }\end{array}$ & 2.2 & 3.9 & 7.3 & 32.3 & 3.5 & 6 & 0.55 & 1.9 \\
\hline $\begin{array}{l}\text { Confidence } \\
\text { interval (CI } \\
95 \%)\end{array}$ & {$[2.6 ; 7.1]$} & [12.1 -19.9] & {$[4.1 ; 18.8]$} & {$[0 ; 63.9]$} & {$[4.8 ; 11.8]$} & {$[13.8 ; 25.9]$} & {$[0.6 ; 1.7]$} & {$[1.4 ; 5.2]$} \\
\hline $\begin{array}{l}\text { Survivors } \\
\text { percentage at } 3 \\
\text { months }\end{array}$ & $62.7 \pm 0.07$ & $85 \pm 0.05$ & $88 \pm 0.08$ & 100 & $95.5 \pm 0.04$ & $93 \pm 0.04$ & $16.7 \pm 0.08$ & $64 \pm 1.3$ \\
\hline $\begin{array}{l}\text { Survivors } \\
\text { percentage }\end{array}$ & $14 \pm 0.06$ & $11 \pm 0.17$ & $65.8 \pm 0.18$ & $40 \pm 0.2$ & $7.6 \pm 0.07$ & $9.8 \pm 0.16$ & 0 & 0 \\
\hline
\end{tabular}

The WHO grade performance status and the nutritional status have been identified as independent factors for a poor prognosis for patients with metastatic pancreatic cancer [24]. Moreover $72.5 \%$ of patients are malnourished, thus use of the G8, which is highly influenced by the nutritional status (7 common items), is a screening tool that is not amenable for use with this specific population.

Few studies have investigated elderly subjects treated for pancreatic cancer. Only retrospective series evaluating the merits of various therapeutics in elderly subjects are available in the literature.

In regard to surgical intervention, in a large retrospective French series(1,300 patients),Turrini et al. did not see a difference in terms of post-operative morbidity-mortality between patients who were $<70$ years of age and those $\geq$ 70 (3.7\% vs. $4.2 \%$ among 875 and 450 patients treated by duododenopancreatectomy, respectively) [25]. In the prospective series of Kow et al. that included 69 patients who underwent a duododenopancreatectomy, there was an increase in the operating time and a higher morbidity was encountered in terms of post-operative pancreatic fistulas with patients $>65$ years of age, relative to patients $<65$ years of age. There was no difference, however, in terms of mortality [26]. Age should hence not be a counter indication for a duododenopancreatectomy, provided that a preoperative assessment is carried out, and that there is a decent level of post-operative follow-up.

The usefulness of performing a preoperative geriatric assessment in addition to the standard preoperative assessment was studied by Dale [27] with 76 elderly patients who had a duododenopancreatectomy. Among these patients, the frailty identified by the Fried score [28] was associated with a higher number of post-operative complications.

In regard to adjuvant treatment, it has been seen both in the French series of Turrini et al. and in a retrospective study performed in the USA with 193 included patients that an adjuvant treatment was given less often to patients over the age of 70 [29], although if surgery had been possible, a treatment with gemcitabine, which doubles the five year survival rate, has a high chance of being tolerated.

For metastatic disease, Vijayvergia et al. retrospectively compared treatment and survival of individuals $<75$ years of age vs. those $\geq 75$ ( 579 patients) [30]. They were able to show that the population over the age of 75 less often received chemotherapy treatments, and that this was more often a mono-chemotherapy relative to the population $<75$ years of age. There was no difference, however, in survival between these two groups, and the Charlson co-morbidity index was not a prognostic factor. The nutritional status (assessed as the blood albumin level), poly-chemotherapy, and a metastatic site were identified as independent prognostic factors in the two groups. In a recent study of an Italian cohort involving 208 patients (ECC-ESMO 2015 - From Giordano G et al., abstr. 2335)treated with a combination of Gemcitabine Nab-Paclitaxel, there was no difference in terms of survival, the response rate, or the tolerance as a function of the age categories ( $<75$ years of age vs. $\geq 75$ years of age).

A large series including 1,914 patients hospitalized for 
treatment of pancreatic cancer (ECC-ESMO 2015 - From Desramé J et al., abstr. 2260)reported that there was no difference in survival based on age ( $<75$ years of age vs. $\geq 75$ years of age) regardless of the therapy (surgery, radio chemotherapy, and chemotherapy).

One of the shortcomings of our study is the small number of subjects, although the data base is active and a further analysis is scheduled.

One of the strengths of our study is the fact that it prospectively describes a frail unselected population that reflects the broader population of elderly subjects seen in everyday practice.

The G8 score, recommended by the French National Cancer Institute (INCa) in the treatment of all elderly patients afflicted with cancer is not suitable with this pathology.

Our study has identified straightforward geriatric parameters (ADL, cognitive impairments, and functional frailty) that affect survival. When used at the time of diagnosis, these allow selection of frail elderly patients for whom BSC is the most appropriate level of care. In the absence of these parameters, elderly patients afflicted with pancreatic cancer are amenable to the same treatments as those provided to younger patients.

These parameters therefore ought to be part of the initial assessment of elderly patients being treated for pancreatic cancer.

\section{References}

1. Jemal A, Siegel R, Ward E, Hao Y, Xu J, Thun MJ. Cancer statistics, 2009. CA Cancer J Clin. 2009;59(4):225-249. doi: 10.3322/caac.20006

2. Ferlay J, Steliarova-Foucher E, Lortet-Tieulent J, Rosso S, Coebergh JW, Comber H, et al. Cancer incidence and mortality patterns in Europe: estimates for 40 countries in 2012. Eur J Cancer Oxf Engl. 2013;49(6):1374-1403. doi: 10.1016/j.ejca.2012.12.027

3. Raimondi S, Maisonneuve P, Lowenfels AB. Epidemiology of pancreatic cancer: an overview. Nat Rev Gastroenterol Hepatol. 2009;6(12):699708. doi: $10.1038 /$ nrgastro.2009.177

4. Baine M, Sahak F, Lin C, Subhankar C, Elizabeth L, Surinder K. Marital status and survival in pancreatic cancer patients: a SEER based analysis. PloS One. 2011;6(6):e21052. doi: 10.1371/journal. pone. 0021052

5. Hidalgo M. Pancreatic cancer. N Engl J Med. 2010;362(17):1605-1617. doi: 10.1056/NEJMra0901557

6. Hentic O, Dreyer C, Rebours V, Zappa M, Lévy P, Raymond E, et al Gemcitabine in elderly patients with advanced pancreatic cancer. World J Gastroenterol. 2011;17(30):3497-3502. doi: 10.3748/wjg. v17.i30.3497

7. Maréchal R, Demols A, Gay F, de Maertelaer V, Arvanitaki M, Hendlisz $A$, et al. Tolerance and efficacy of gemcitabine and gemcitabinebased regimens in elderly patients with advanced pancreatic cancer. Pancreas. 2008;36(3):e16-21. doi: 10.1097/MPA.0b013e31815f3920

8. Yukisawa S, Ishii H, Matsuyama M, Kuraoka K, Takano K, Kamei A, et al. Outcomes and tolerability of systemic chemotherapy for pancreatic or biliary cancer patients aged 75 years or older. Jpn J Clin Oncol. 2011;41(1):76-80. doi: 10.1093/jjco/hyq160
9. Conroy T, Desseigne F, Ychou M, Bouché O, Guimbaud R, Bécouarn Y, et al. FOLFIRINOX versus gemcitabine for metastatic pancreatic cancer. $N$ Engl J Med. 2011;364(19):1817-1825. doi: 10.1056/NEJMoa1011923

10. Jacobson SD, Alberts SR, O'Connell MJ. Pancreatic cancer in the older patient. Oncol Williston Park N. 2001;15:926-932-937.

11. Oziel-Taieb S, Faure M, Gilabert M, Autret A, Turrini O, MoureauZabotto L, et al. Treatment of Pancreatic Adenocarcinoma in Elderly Patients over 75 Years of Age: A Retrospective Series of 129 Patients. J Gastrointest Cancer. 2016;47(1):15-19. doi: 10.1007/s12029-0159774-4

12. Katz S, Ford AB, Moskowitz RW, Jackson BA, Jaffe MW et al. STUDIES OF ILLNESS IN THE AGED. THE INDEX OF ADL: A STANDARDIZED MEASURE OF BIOLOGICAL AND PSYCHOSOCIAL FUNCTION. JAMA. 1963;185:914-919.

13. Lawton MP, Brody EM. Assessment of older people: self-maintaining and instrumental activities of daily living. The Gerontologist. 1969;9:179-186.

14. Podsiadlo D, Richardson S. The timed "Up \& Go": a test of basic functional mobility for frail elderly persons. J Am Geriatr Soc. 1991;39(2):142-148.

15. Mathias S, Nayak US, Isaacs B. Balance in elderly patients: the "get-up and go" test. Arch Phys Med Rehabil. 1986;67:387-389.

16. Studenski S, Perera S, Patel K, Rosano C, Faulkner K, Inzitari M, et al. Gait speed and survival in older adults. JAMA. 2011;305:50-58. doi: 10.1001/jama.2010.1923

17. Vellas BJ, Wayne SJ, Romero L, Baumgartner RN, Rubenstein LZ, Garry PJ. One-leg balance is an important predictor of injurious falls in older persons. J Am Geriatr Soc. 1997;45:735-738.

18. Folstein MF, Folstein SE, McHugh PR. "Mini-mental state”. A practical method for grading the cognitive state of patients for the clinician. J Psychiatr Res. 1975;12(3):189-198.

19. Yesavage JA. Geriatric Depression Scale. Psychopharmacol Bull. 1988;24:709-711.

20. Soubeyran P, Bellera C, Goyard J, Heitz D ,Curé H, Rousselot H, et al. Screening for vulnerability in older cancer patients: the ONCODAGE Prospective Multicenter Cohort Study. PLoS One. 2014;9(12):e115060. doi: 10.1371/journal.pone. 0115060

21. Bellera CA, Rainfray M, Mathoulin-Pélissier S, Mertens C, Delva F, Fonck M, et al. Screening older cancer patients: first evaluation of the G-8 geriatric screening tool. Ann Oncol. 2012;23(8):2166-2172.

22. Balducci L, Extermann M. Management of cancer in the older person: a practical approach. Oncologist. 2000;5(3):224-237.

23. Charlson ME, Pompei P, Ales KL, MacKenzie CR. A new method of classifying prognostic comorbidity in longitudinal studies: development and validation. J Chronic Dis. 1987;40(5):373-383.

24.Gourgou-Bourgade S, Bascoul-Mollevi C, Desseigne F, Ychou M, Bouché O, Guimbaud R, et al. Impact of FOLFIRINOX compared with gemcitabine on quality of life in patients with metastatic pancreatic cancer: results from the PRODIGE 4/ACCORD 11 randomized trial. J Clin Oncol .2013;31(1):23-29. doi: 10.1200/JC0.2012.44.4869

25. Turrini O, Paye F, Bachellier P, Sauvanet A, Sa Cunha A, Le Treut YP, et al. Pancreatectomy for adenocarcinoma in elderly patients: postoperative outcomes and long term results: a study of the French Surgical Association. Eur J Surg Oncol. 2013;39(2):171-178. doi: 10.1016/j.ejso.2012.08.017 
26. Kow AWC, Sadayan NA, Ernest A, B.Wang, C.Y.Chan, C.K.Ho, et al.Is pancreaticoduodenectomy justified in elderly patients? Surgeon. 2012;10(3):128-136. doi: 10.1016/j.surge.2011.02.005

27. Dale W, Hemmerich J, Kamm A, Posner MC, Matthews JB, Rothman R, et al. Geriatric assessment improves prediction of surgical outcomes in older adults undergoing pancreaticoduodenectomy: a prospective cohort study. Ann Surg. 2014;259(5):960-965. doi: 10.1097/ SLA.0000000000000226

28. Fried LP, Tangen CM, Walston J, Newman AB, Hirsch C, Gottdiener J, et al. Frailty in older adults: evidence for a phenotype. J Gerontol A Biol Sci Med Sci. 2001;56(3):M146-M156.
29. Frakes JM, Strom T, Springett GM, Hoffe SE, Balducci L, Hodul P, et al. Resected pancreatic cancer outcomes in the elderly. J Geriatr Oncol. 2015;6(2):127-132.

30. Vijayvergia N, Dotan E, Devarajan K, Hatahet K, Rahman F, Ricco J, et al. Patterns of care and outcomes of older versus younger patients with metastatic pancreatic cancer: A Fox Chase Cancer Center experience. J Geriatr Oncol. 2015;6(6):454-461. doi: 10.1016/j.jgo.2015.08.001 